\title{
Cytokine-induced killer cell/dendritic cell combined with cytokine-induced killer cell immunotherapy for treating advanced gastrointestinal cancer
}

Hansong Du ${ }^{1 \dagger}$, Jia Yang ${ }^{1 \dagger}$ and Ying Zhang ${ }^{2^{*}}$

\begin{abstract}
Background: This study aimed to investigate the efficacy and safety of cytokine-induced killer (CIK)/dendritic cell combined with CIK (DC-CIK) cell therapy in advanced gastrointestinal cancer (GIC).

Methods: The PubMed, Cochrane library, and Embase were searched to conduct a meta-analysis of clinical controlled trials to evaluate the efficacy and safety of CIK/DC-CIK cell therapy in advanced GIC. The pooled risk ratios (RRs) or weighted mean difference (WMD) with 95\% confidence intervals (95\% Cls) were calculated.

Results: A total of nine studies with 1113 patients were identified. The overall survival ( $R R=1.84,95 \% \mathrm{Cl}=1.41-2.40$, $\left.P_{\text {heterogeneity }}=0.654, P^{2}=0 \%\right)$, progression-free survival $\left(R R=1.99,95 \% C l=1.52-2.60, P_{\text {heterogeneity }}=0.727, P=0 \%\right)$, and quality of life $\left(\mathrm{WMD}=16.09,95 \% \mathrm{Cl}=1.66-30.52\right.$, $\left.P_{\text {heterogeneity }}<0.001, P^{2}=98.8 \%\right)$ were significantly improved in patients who received chemotherapy combined with CIK/DC-CIK cells, and no severe adverse events were reported.

Conclusion: This meta-analysis suggested that the combination of CIK/DC-CIK immunotherapy and chemotherapy was safe and applicable for patients with advanced GIC. It is a feasible choice to prolong survival and improve quality of life.
\end{abstract}

Keywords: Advanced gastrointestinal cancer, Cytokine-induced killer, Dendritic cell, Meta-analysis, Systematic review

\section{Background}

Gastrointestinal cancers (GICs) are one of the leading causes of cancer-related mortality in the world, which majorly include cancers of colorectum and stomach (CRC and GC). In addition to growth and aging of global population, behavioral risk factors, such as smoking and dietary patterns, played an important role in the

\footnotetext{
* Correspondence: zzhangying@hust.edu.cn

† Hansong Du and Jia Yang contributed equally to this work.

${ }^{2}$ Department of Biochemistry \& Molecular Biology, School of Basic Medicine,

Tongji Medical College, Huazhong University of Science and Technology, Wuhan, China

Full list of author information is available at the end of the article
}

rising global burden of GIC [1]. Many treatment strategies, such as surgery, neoadjuvant chemotherapy, and adjuvant chemotherapy [2], are available for GIC patients. Moreover, early GIC patients can be cured by appropriate treatment, and the 5-year overall survival (OS) rate is $90 \%$; however, for patients with advanced-stage GIC, the 5-year OC rate is still very low [3, 4].

Surgery, radiotherapy, and chemotherapy are routine treatments for GIC in most patients; they have the efficacy of eliminating and destroying primary tumors. However, these traditional treatments are often ineffective for advanced-stage cancers [5]. Cancer immunotherapy is a promising treatment method, which has made great progress in improving anti-tumor immunity [6].

(c) The Author(s). 2020 Open Access This article is licensed under a Creative Commons Attribution 4.0 International License, which permits use, sharing, adaptation, distribution and reproduction in any medium or format, as long as you give appropriate credit to the original author(s) and the source, provide a link to the Creative Commons licence, and indicate if changes were made. The images or other third party material in this article are included in the article's Creative Commons licence, unless indicated otherwise in a credit line to the material. If material is not included in the article's Creative Commons licence and your intended use is not permitted by statutory regulation or exceeds the permitted use, you will need to obtain permission directly from the copyright holder. To view a copy of this licence, visit http://creativecommons.org/licenses/by/4.0/. The Creative Commons Public Domain Dedication waiver (http://creativecommons.org/publicdomain/zero/1.0/) applies to the data made available in this article, unless otherwise stated in a credit line to the data. 
Autoimmune therapy for malignant tumors is considered to be a feasible method, which mainly depends on the interference and inhibition effects of killer cells induced by the tumor, infiltrating lymphocytes and lymphokines, and CD3 monoclonal antibody [7, 8]. Dendritic cells (DCs) have the ability to present antigens, making them an attractive vehicle for the delivery and development of therapeutic tumor vaccines [9] . Cytokine-induced killer cells (CIK) is a heterogeneous effector CD3 + CD56 + NKT cell population that can be expanded from peripheral blood mononuclear cells (PBMC) in vitro [10, 11]. CIK cells have a strong MHC non-restrictive cytotoxicity, which inhibits both blood and solid malignancies, identifying and killing tumor targets without exposure or initiation. At present, CIK therapy or DC-CIK cell co-cultivation has been broadly applied in clinical trials for the treatment of GICs [1220]; however, the results are not entirely consistent. Therefore, we conducted a systematic review and metaanalysis of published literature to evaluate the efficacy and safety of CIK/DC-CIK cells combined with chemotherapy for the treatment with advanced GIC cancer.

\section{Methods}

\section{Literature search}

The databases PubMed, Cochrane library, and Embase were searched for all relevant studies published in English. The search terms included "dendritic cells," "immunotherapy," "cytokine induced killer cells" OR "DCCIK" combined with "colon OR rectal OR colorectal OR gastric cancer/tumor/carcinoma/neoplasm." The last research was updated on January 1, 2019. The reference lists of all retrieved studies and published reviews were searched manually for additional references, and all identified relevant studies were included.

\section{Study selection}

The inclusion criteria were as follows: (1) clinical controlled trials of patients with CRC or GC; (2) patients pathologically diagnosed with Tumor Node Metastasis (TNM) stages of II, III, and IV; and (3) patients in the experimental group treated using chemotherapy combined with CIK or DC-CIK immunotherapy, whereas patients in the control group treated using chemotherapy alone. The exclusion criteria were as follows: (1) reviews, conference abstracts, letter, or case reports; (2) multiple studies published on the same population (in which case the most recent and complete study was included); and (3) studies without available data for statistics. The studies meeting at least one of the aforementioned three criteria were excluded.

\section{Data extraction and quality assessment}

The following data from each study were extracted independently by two authors: authors, year of publication, sample size, chemotherapy regimen, follow-up period, curative effect, and adverse events of each eligible trial. The primary endpoints were OS and progression-free survival (PFS). The other endpoints were complete response (CR), partial response (PR), overall response rate (ORR), and quality of life (QOL). Safety analyses were also performed. Two reviewers independently extracted the studies. Any disagreements were resolved by consensus. Evaluation of the research quality was managed using the Cochrane Collaboration's tool for assessing risk of bias.

\section{Statistical analysis}

The meta-analysis was conducted using Stata 14.0 (Stata Corp., TX, USA). Risk ratios (RRs) or weighted mean difference (WMD) with 95\% confidence intervals (CIs) were calculated as effect sizes. RR was the effect measurement for dichotomous outcomes, while WMD was applied for the continuous variables. The potential heterogeneity across studies was examined via Cochran's Q-statistic and $I^{2}$ statistics. The $P$ value for heterogeneity $<0.1$ indicated that the heterogeneity was statistically significant. Thus, the random-effects model was used to perform the analysis. Otherwise, the summary effect was computed using the fixed-effects model. In the sensitivity analysis, the influence of each study on the summary effect was analyzed by dropping one study at a time. The Begg's and Egger's tests were conducted to evaluate publication bias. The trim-and-fill method was used to determine the effect of potential publication bias on the pooled estimates. A $P$ value less than 0.05 was considered to be statistically significant.

\section{Results}

\section{Literature search and study selection}

A total of 466 studies were identified from PubMed, Cochrane library, and Embase. Then, three additional records were found by manually searching the reference lists of other studies. After deleting the duplications, 351 studies were selected. Then, 330 studies were discarded because of their irrelevance to the topic of interest. Of the remaining 21 studies, 3 were excluded for unavailability of data for statistics and four were excluded as they did not include controls. Besides, five studies did not focus on the advancedstage GIC. Finally, a total of nine studies, including 1113 patients, met the inclusion and exclusion criteria in this meta-analysis ${ }^{11-19}$. The flow diagram of the search process is shown in Fig. 1. 


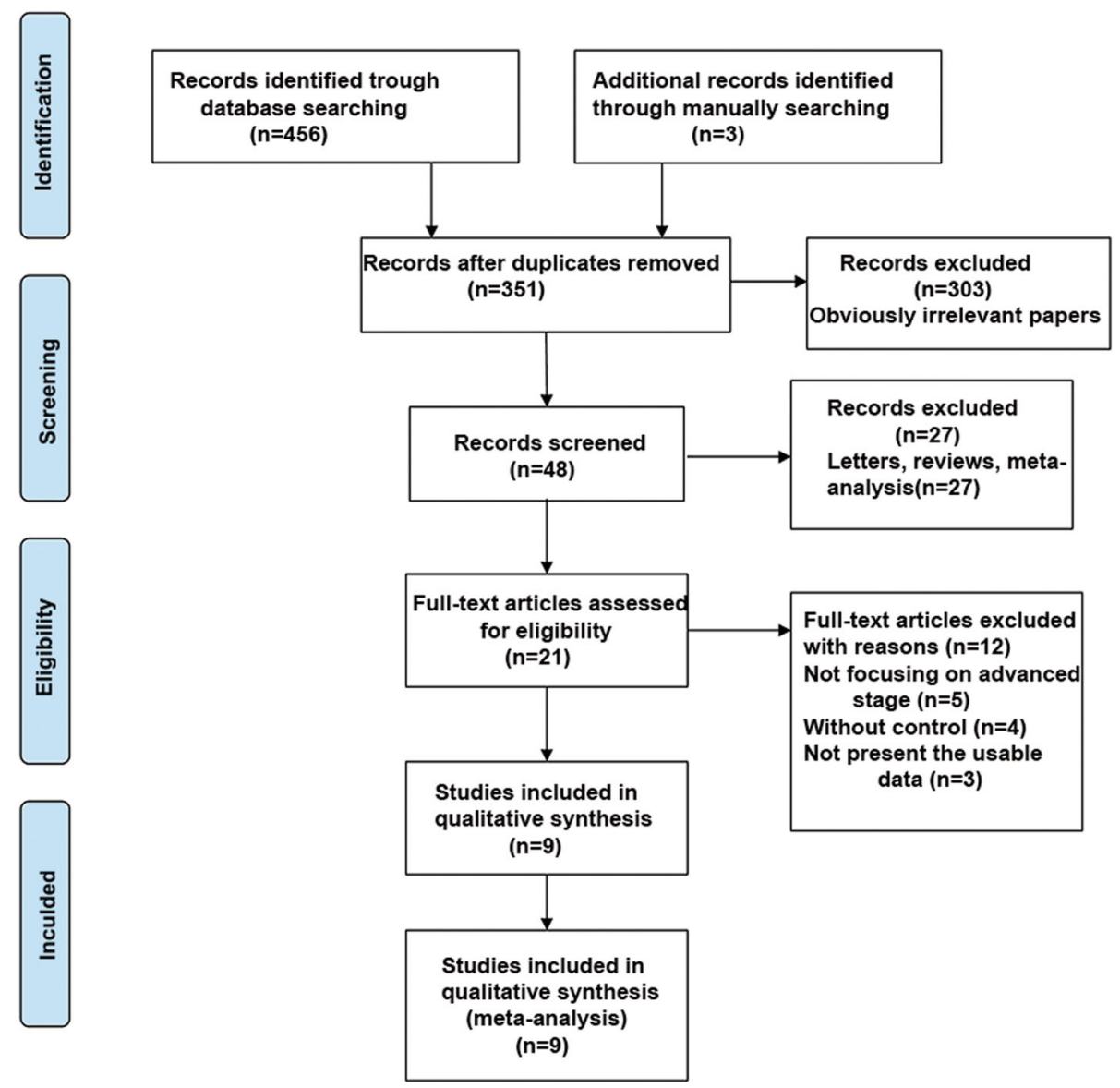

Fig. 1 Flow diagram of study identification

\section{Study characteristics}

The key characteristics of all included studies are summarized in Table 1. All the studies involved patients with advanced GIC followed up for at least 24 months. Nine studies from 2006 to 2017 compared CIK/DC-CIK plus chemotherapy with chemotherapy alone for treating advanced GIC. These nine studies were assessed using the Cochrane Collaboration's tool for the risk of bias. A graph and summary of the risk of bias are shown in Figs. 2 and 3 . Four studies did not mention randomization, and three studies did not provide information of allocation concealment.

\section{Meta-analyses \\ Efficacy}

Clinical responses were assessed in terms of the OS and PFS to evaluate the prognosis.

Among the nine trials, three reported 1-year OS rate, five reported 3-year OS rate, and four reported 5-year OS rate (Fig. 3a). As a slightly significant heterogeneity was detected, the fixed-effects model was used. Chemotherapy combined with CIK/DC-CIK immunotherapy showed a significant increase in 1-year OS (3 studies,
292 patients, $\mathrm{RR}=1.43,95 \% \mathrm{CI}=1.23-1.66, P_{\text {heterogene- }}$ ity $=0.310, I^{2}=14.6 \%$ ), 3-year OS (5 studies, 727 patients, $\mathrm{RR}=1.43,95 \% \mathrm{CI}=1.25-1.64, P_{\text {heterogeneity }}=0.179, I^{2}=$ $36.3 \%$ ), and 5 -year OS (4 studies, 580 patients, $R R=1.84$, 95\% CI $\left.=1.41-2.40, \quad P_{\text {heterogeneity }}=0.654, I^{2}=0 \%\right)$ compared with those of chemotherapy alone.

In terms of PFS, three studies presented relevant data of 1-year PFS, five reported 3-year PFS, and four reported 5-year PFS. As shown in Fig. 3b, chemotherapy combined with immunotherapy significantly prolonged 1-year PFS (3 studies, 292 patients, $\mathrm{RR}=1.34,95 \% \mathrm{CI}=$ $\left.1.13-1.59, P_{\text {heterogeneity }}=0.972, I^{2}=0 \%\right)$, 3-year PFS $(5$ studies, 727 patients, $\mathrm{RR}=1.39,95 \% \mathrm{CI}=1.20-1.62, P_{\text {he- }}$ terogeneity $=0.664, I^{2}=0 \%$ ), and 5-year PFS (4 studies, 580 patients, $\mathrm{RR}=1.99,95 \% \mathrm{CI}=1.52-2.60, \quad P_{\text {heterogeneity }}=$ $\left.0.727, I^{2}=0 \%\right)$ compared with chemotherapy alone.

\section{Efficacy}

Efficacy was assessed in terms of CR, PR, and ORR. The analysis result is shown in Fig. 4; however, the RR of CR (3 studies, 207 patients, $\mathrm{RR}=1.89,95 \% \mathrm{CI}=0.18-20.20$ ), PR (3 studies, 207 patients, $\mathrm{RR}=1.86,95 \% \mathrm{CI}=0.93-$ $3.71, P_{\text {heterogeneity }}=0.773, I^{2}=0 \%$ ), and ORR (3 studies, 


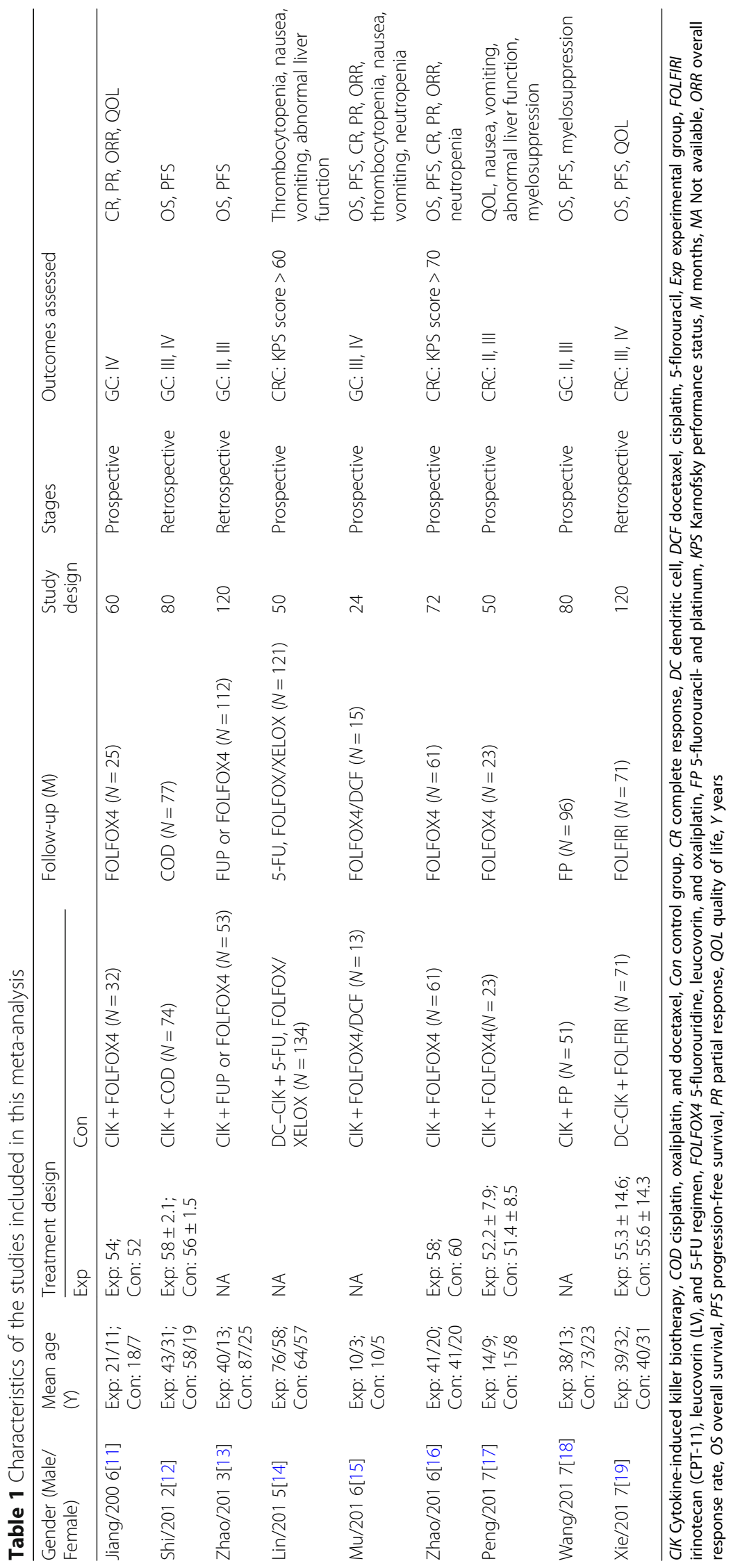



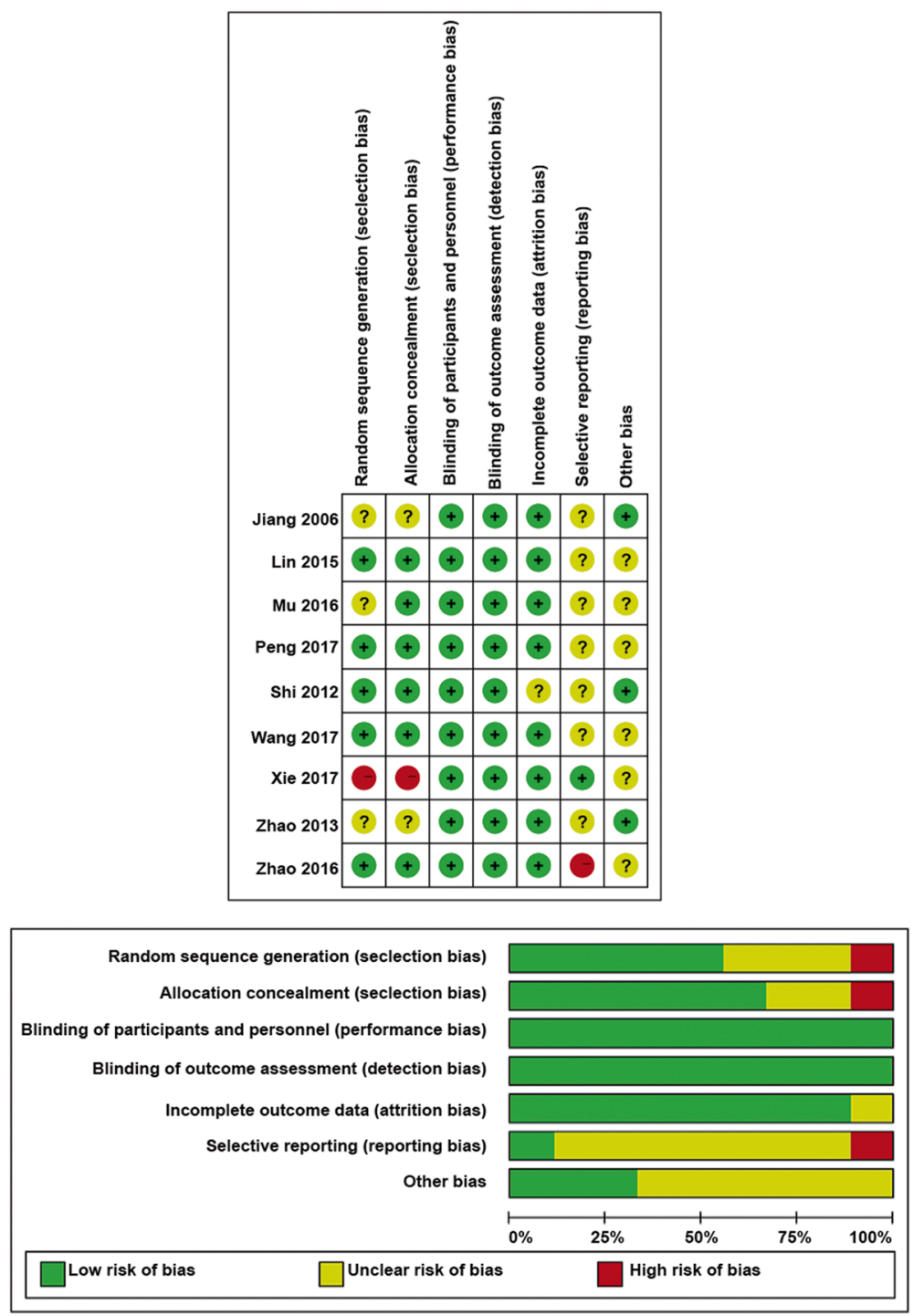

Fig. 2 Risk-of-bias assessments for the randomized trials included in the meta-analysis. a Risk-of-bias summary. b Risk-of-bias graph. Symbols: (+), Low risk of bias; (?), unclear risk of bias; and (-), high risk of bias

207 patients, $\mathrm{RR}=1.51,95 \% \mathrm{CI}=0.97-2.37, P_{\text {heterogene- }}$ ity $\left.=0.417, I^{2}=0 \%\right)$ did not infer significant difference between the two groups. Three studies evaluated the effect of CIK/DC-CIK immunotherapy on the QOL of patients with advanced GIC. Significantly improved QOL was found in the CIK/DC-CIK immunotherapy group compared with the chemotherapy-alone group (3 studies, 245 patients, $\mathrm{WMD}=16.09,95 \% \mathrm{CI}=1.66-30.52, P_{\text {hetero- }}$ geneity $<0.001, I^{2}=98.8 \%$ ) (Figure S1).

The safety of CIK/DC-CIK therapy in the treatment of advanced GIC was evaluated in this meta-analysis. As shown in Figure S2, no significant difference was observed in terms of thrombocytopenia (2 studies, 283 patients, $\quad \mathrm{RR}=1.04,95 \% \mathrm{CI}=0.93-1.16, \quad P_{\text {heterogeneity }}=$ $0.497, I^{2}=0 \%$ ), nausea, vomiting ( 3 studies, 329 patients,
$\mathrm{RR}=0.67,95 \% \mathrm{CI}=0.35-1.28, P_{\text {heterogeneity }}=0.003, I^{2}=$ $82.9 \%$ ), abnormal liver function (2 studies, 301 patients, $\mathrm{RR}=1.08,95 \% \mathrm{CI}=0.95-1.23, P_{\text {heterogeneity }}=0.373, I^{2}=$ $0 \%$ ), neutropenia ( 2 studies, 150 cases, $\mathrm{RR}=0.55,95 \%$ $\mathrm{CI}=0.31-1.00, P_{\text {heterogeneity }}=0.955, I^{2}=0 \%$ ), and myelosuppression ( 2 studies, 193 patients, $\mathrm{RR}=0.73,95 \% \mathrm{CI}=$ $0.48-1.11, P_{\text {heterogeneity }}=0.088, I^{2}=65.7 \%$ ) between the two groups.

\section{Subgroup analysis}

This study probed the detailed results in subgroup analyses stratified by cancer type (GC or CRC). All subgroup results were quite consistent with the overall results. The results are summarized in Table 2. 
A

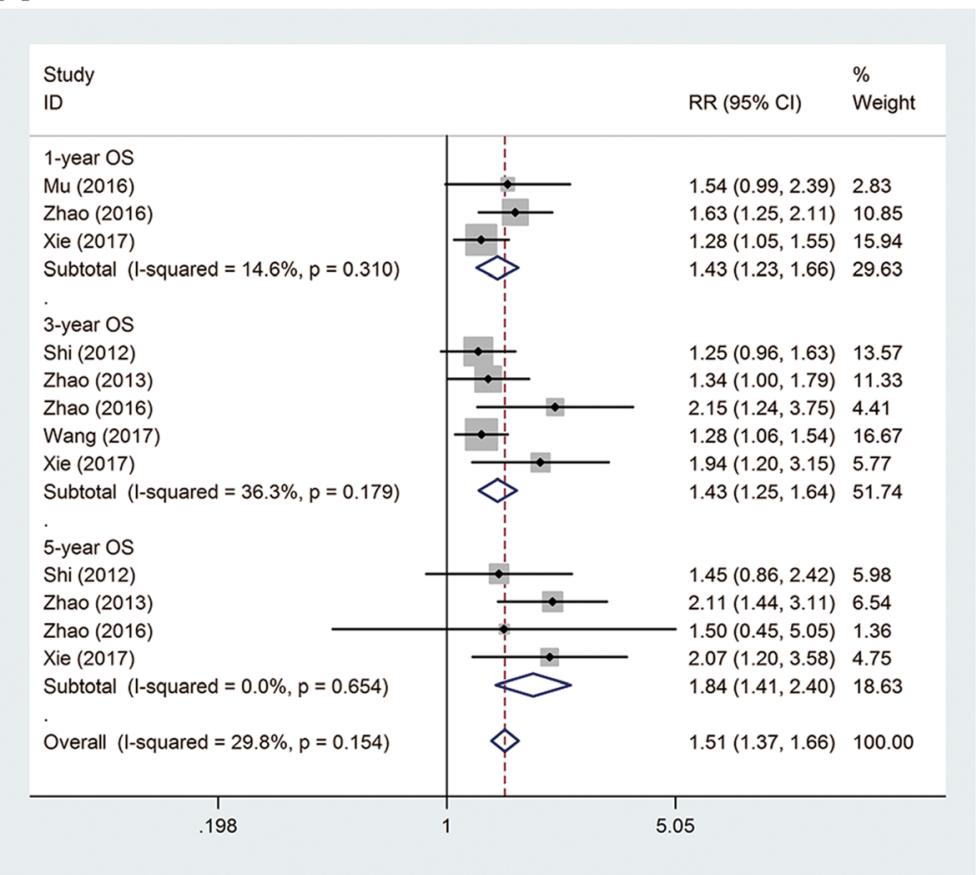

B

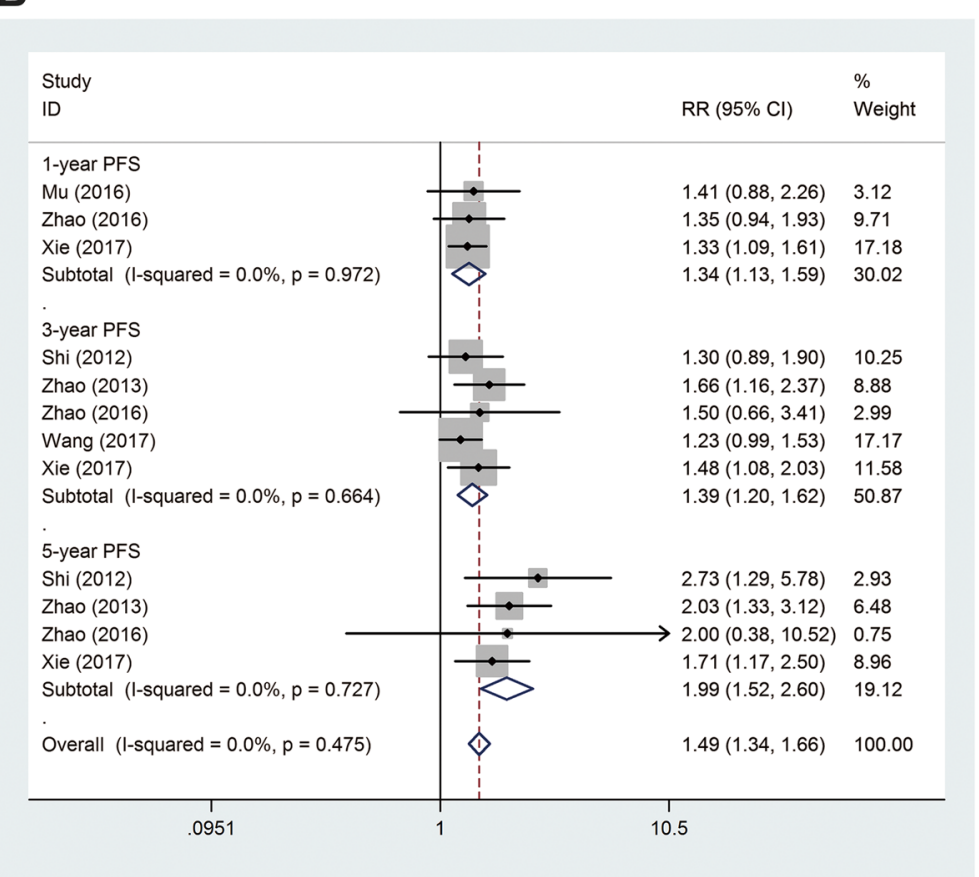

Fig. 3 Forest plot of the comparison of survival. a Overall survival (OS). b Progression-free survival

\section{Sensitivity analysis}

Sensitivity analyses were performed to assess the stability of the results by sequentially removing each study. The removal of any single study did not change the overall statistical results, indicating that the results of this study were statistically robust (Fig. 5).

\section{Publication bias}

The outcome of OS, with the largest number of included studies, was chosen to test the publication bias. Visual examination of the funnel plot (Fig. 6a) revealed a considerable degree of asymmetry. In addition, publication bias was statistically significant by Egger's test or Begg's 


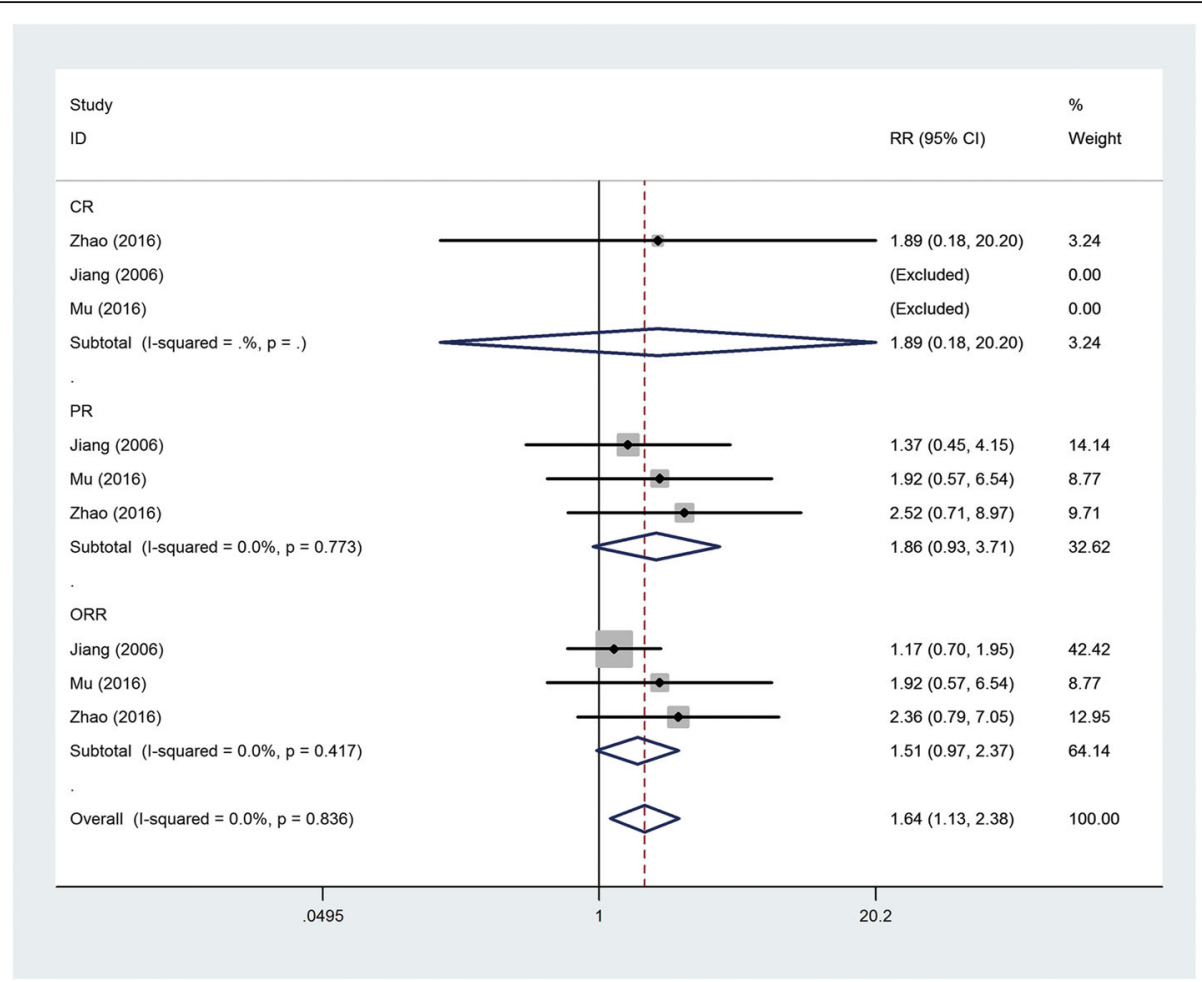

Fig. 4 Forest plot of the comparison of complete response (CR), partial response (PR), and overall response rate (ORR)

Table 2 Subgroup analysis based on cancer type

\begin{tabular}{|c|c|c|c|c|c|}
\hline Outcome & Subgroup & Number of trials & Effect $(95 \% \mathrm{Cl})$ & Overall effect estimate & Heterogeneity \\
\hline \multirow[t]{2}{*}{ 1-Year OS } & GC & 1 & $1.54(0.99,2.39)$ & $P=0.056$ & - \\
\hline & CRC & 2 & $1.42(1.21,1.66)$ & $P<0.001$ & $P^{2}=54.1 \%, P=0.140$ \\
\hline \multirow[t]{2}{*}{ 3-Year OS } & GC & 3 & $1.29(1.12,1.48)$ & $P<0.001$ & $P^{2}=0 \%, P=0.937$ \\
\hline & $C R C$ & 2 & $2.03(1.41,2.93)$ & $P<0.001$ & $P^{2}=0 \%, P=0.782$ \\
\hline \multirow[t]{2}{*}{ 5-Year OS } & GC & 2 & $1.79(1.31,2.45)$ & $P<0.001$ & $P^{2}=26.8 \%, P=0.242$ \\
\hline & CRC & 2 & $1.94(1.18,3.20)$ & $P=0.009$ & $P^{2}=0 \%, P=0.634$ \\
\hline \multirow[t]{2}{*}{ 1-Year PFS } & GC & 1 & $1.41(0.88,2.26)$ & $P=0.155$ & - \\
\hline & $C R C$ & 2 & $1.33(1.11,1.60)$ & $P=0.002$ & $P^{2}=0 \%, P=0.940$ \\
\hline \multirow[t]{2}{*}{ 3-Year PFS } & GC & 3 & $1.36(1.14,1.61)$ & $P=0.001$ & $P^{2}=0 \%, P=0.377$ \\
\hline & CRC & 2 & $1.49(1.10,2.01)$ & $P=0.010$ & $P^{2}=0 \%, P=0.980$ \\
\hline \multirow[t]{2}{*}{ 5-Year PFS } & GC & 2 & $2.25(1.54,3.29)$ & $P<0.001$ & $P^{2}=0 \%, P=0.493$ \\
\hline & CRC & 2 & $1.73(1.19,2.52)$ & $P=0.004$ & $P^{2}=0 \%, P=0.854$ \\
\hline \multirow[t]{2}{*}{$P R$} & GC & 2 & $1.58(0.70,3.59)$ & $P=0.275$ & $P^{2}=0 \%, P=0.685$ \\
\hline & CRC & 1 & $2.52(0.71,8.97)$ & $P=0.154$ & - \\
\hline \multirow[t]{2}{*}{ ORR } & GC & 2 & $1.30(0.81,2.09)$ & $P=0.278$ & $P^{2}=0 \%, P=0.457$ \\
\hline & CRC & 1 & $2.36(0.79,7.05)$ & $P=0.124$ & - \\
\hline \multirow[t]{2}{*}{$\mathrm{QOL}$} & GC & 1 & $28(26.36,29.64)$ & $P<0.001$ & - \\
\hline & CRC & 2 & $9.32(6.96,11.69)$ & $P<0.001$ & $P^{2}=0 \%, P=0.373$ \\
\hline
\end{tabular}

CRC Colorectal cancer, GC gastric cancer, ORR overall response rate, OS overall survival, $P F S$ progression-free survival, $P R$ partial response, $Q O L$ quality of life 

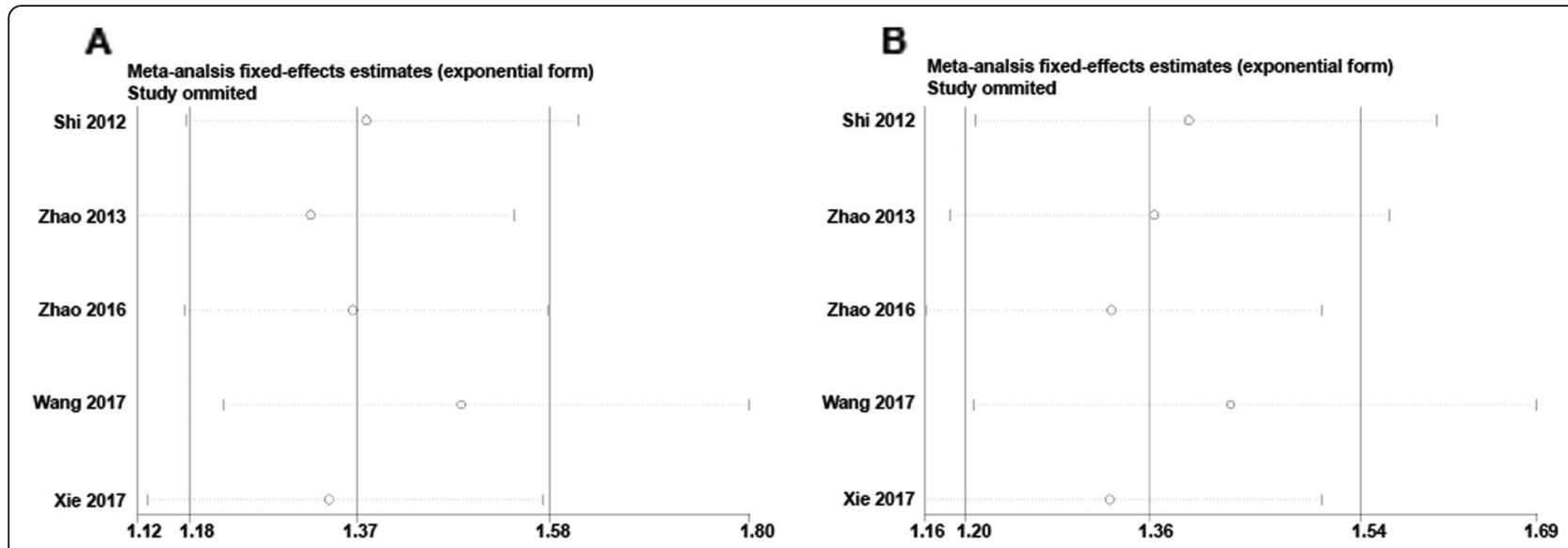

\section{C}

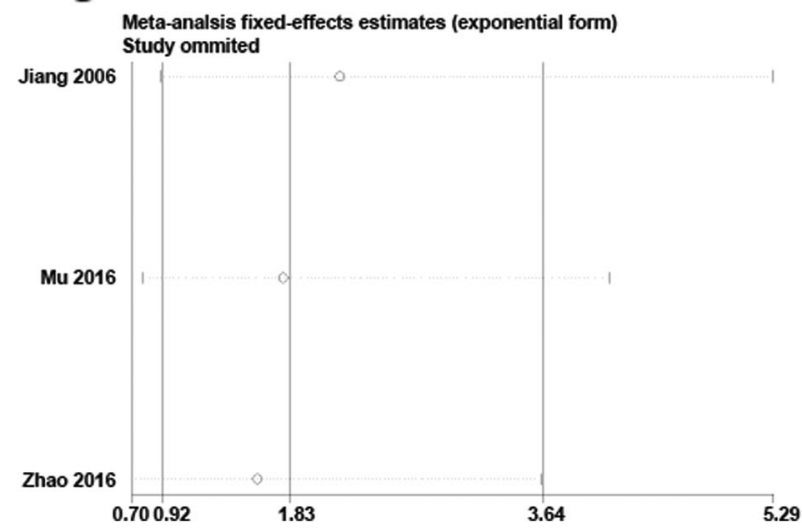

D

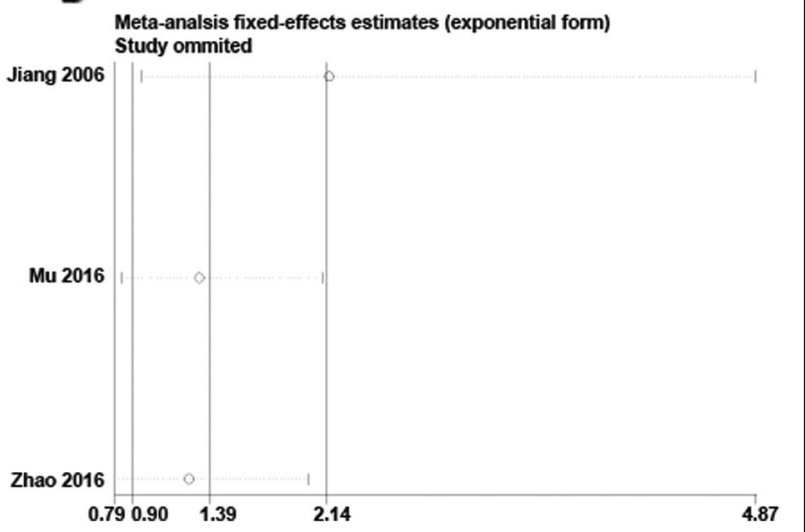

Fig. 5 Sensitivity analysis examining the influence of individual study on pooled results. a Overall survival. b Progression-free survival. c Partial response. $\mathbf{d}$ Overall response rate

test (Begg's test, $P=0.034$; Egger's test, $P=0.016$ ). Therefore, a sensitivity analysis was conducted using the trim-and-fill method (Fig. 6b) [21]. After imputing six unpublished studies, the trim and fill sensitivity analysis did not change the general result $(\mathrm{RR}=0.255,95 \% \mathrm{CI}=$ 0.176-0.333, $P<0.01)$.

\section{Discussion}

GIC is still a fatal threat to human health due to metastasis, with recurrence inducing refractory advanced tumor stage and poor prognosis. Yan et al. [22] proved that the recurrence rate of patients with GC ranged from 40 to $65 \%$ due to distant metastasis and local recurrence. Adoptive cellular immunotherapy can be used in combination with standard therapy as adjuvant and palliative treatment after operation to improve the survival rate and QOL of patients with GIC. The CIK cells have shown the best efficacy in this treatment. Compared with lymphokine-activated killer cells, CIK cells are more readily available and show higher tumor-specific cytotoxic activity [23-27]. To date, several clinical trials have used chemotherapy plus DC-CIK immunotherapy to treat advanced GIC. However, in these trials, the clinical protocol applied was not standard, blurring the evaluation of treatment effects. In this study, a large number of comprehensive trials were investigated to achieve higher statistical reliability. This meta-analysis showed that chemotherapy combined with CIK/DCCIK immunotherapy improved the OS, PFS, and QOL without causing serious adverse events.

This study confirmed the safety of CIK/DC-CIK immunotherapy for advanced GIC patients, and the adverse events caused were tolerated by all patients. No significant difference was observed in terms of common adverse events, such as thrombocytopenia $(\mathrm{RR}=1.04,95 \% \mathrm{CI}=$ $0.93-1.16, P_{\text {heterogeneity }}=0.497, I^{2}=0 \%$, nausea, vomiting $\left(\mathrm{RR}=0.67,95 \% \mathrm{CI}=0.35-1.28, P_{\text {heterogeneity }}=0.003, I^{2}=\right.$ $82.9 \%)$, abnormal liver function $(\mathrm{RR}=1.08,95 \% \mathrm{CI}=$ $\left.0.95-1.23, P_{\text {heterogeneity }}=0.373, I^{2}=0 \%\right)$, neutropenia $(\mathrm{RR}=$ $\left.0.55,95 \% \mathrm{CI}=0.31-1.00, P_{\text {heterogeneity }}=0.955, I^{2}=0 \%\right)$, and myelosuppression $\left(\mathrm{RR}=0.73,95 \% \mathrm{CI}=0.48-1.11, P_{\text {he- }}\right.$ terogeneity $\left.=0.088, I^{2}=65.7 \%\right)$ in the CIK/DC-CIK immunotherapy group compared with the chemotherapyalone group. The CIK/DC-CIK immunotherapy enhanced 


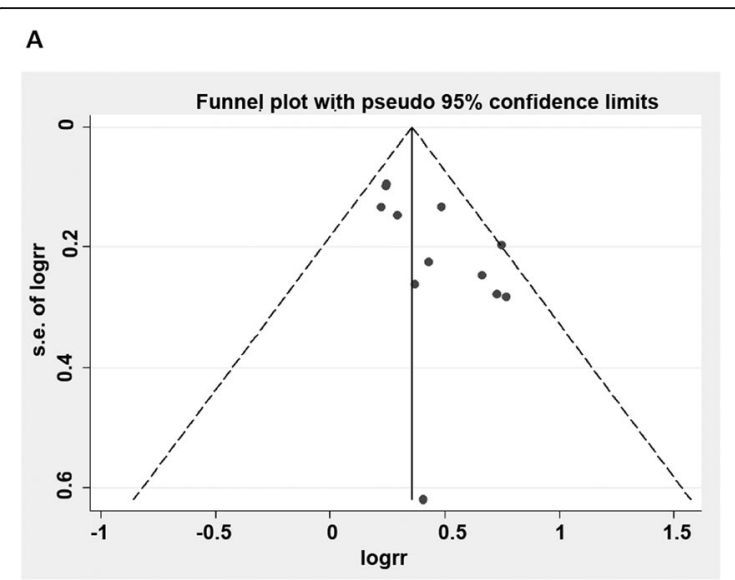

B

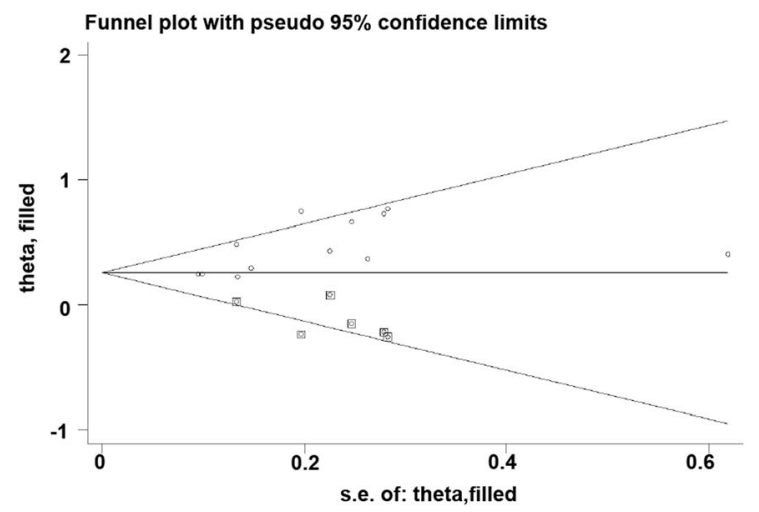

Fig. 6 Funnel plot for publication bias. Each point represents a separate study for the indicated association. a Funnel plot of OS. $\mathbf{b}$ Trim-and-fill plot of OS

the efficiency of conventional therapy in treating advanced GIC. Compared with the conventional therapy group, the 1-year OS, 3-year OS, 5-year OS, 1-year PFS, 3-year PFS, and 5-year PFS of patients in the combination therapy group improved remarkably. Moreover, the combination therapy improved the QOL $(\mathrm{WMD}=16.09,95 \% \mathrm{CI}=$ $\left.1.66-30.52, P_{\text {heterogeneity }}<0.001, I^{2}=98.8 \%\right)$ of the patients by relieving pain, decreasing fatigue and insomnia, and improving appetite.

Chemotherapy is thought to damage the immune system. Immunotherapy is a type of cancer treatment that helps the body's own immune system fight cancer, many clinical trials of immunotherapy have been conducted in multiple centers. DCs are an important immunotherapeutic cell type. Ishigami et al. [28] demonstrated that patients with GC having a high level of DC cell infiltration were less likely to have lymph node metastasis and a significantly increased 5-year survival rate. In addition, CIK cells exhibit strong cytotoxicity against a variety of tumor cell lines as well as newly isolated tumor samples (e.g. liver cancer [29], lung cancer [30], glioma [31], and GC [32]). Compared with other immune cells, CIK cells proliferate rapidly and exhibit strong antitumor activity and a broad spectrum of targeted tumors [14, 33]. Therefore, CIK/DC-CIK cell-based immunotherapy is a promising treatment for a number of cancers. Zhao et al. [34] showed that "GP regimen combined with DCCIK immunotherapy could reduce postoperative recurrence and prolong survival in patients with non-smallcell lung cancer." Ma et al. [35] demonstrated that CIK cell therapy had significant advantages in prolonging the median OS rate, PFS, DCR, ORR, and QOL of patients with hepatocellular carcinoma. Other studies of gastric cancer [13], advanced renal cancer [36], and metastatic nasopharyngeal carcinoma [37] demonstrated that DCCIK cells could improve the prognosis of patients. CIK cells have become a promising immunotherapy method in tumor therapy due to their easy availability and strong antitumor activity, which is of great significance for tumor prognosis [38].

Heterogeneity is a problem with most meta-analyses. In the present meta-analysis, heterogeneity was found in overall analyses; thus, the random-effects model was used. Sensitivity analysis was performed to assess the stability of the results by sequentially removing each study. The removal of any single study did not change the overall statistical results, indicating that the results of this study were statistically robust. Furthermore, this study probed the detailed results in subgroup analyses stratified by cancer type (GC or CRC). Based on the data collected, this study suggested that the cancer type at least partly contributed to the between-study heterogeneity.

This meta-analysis had some limitations that might have affected the interpretation of results. First, the efficacy of CIK/DC-CIK immunotherapy was affected by many factors, such as injection mode, tumor stage, and metastasis cycle. Further, a detailed analysis needs to be carried out on the basis of complete literature, standardization of treatment options, and limitation of patient participation criteria. Second, some data on adverse events could only be used in two trials, which might have led to bias. Third, publishing bias existed in this study. Although the trim-and-fill method was used in this study to confirm the results, some negative data that were possibly omitted might have affected the results. Finally, the heterogeneity could not be completely eliminated in the analysis.

\section{Conclusion}

In summary, this meta-analysis confirmed that the combination of CIK/DC-CIK immunotherapy and chemotherapy was safe and applicable for patients with advanced GIC, and hence might serve a feasible choice to prolong survival and improve QOL. Therefore, CIK/ DC-CIK immunotherapy is an effective therapy for advanced GIC treatment. 


\section{Supplementary information}

Supplementary information accompanies this paper at https://doi.org/10. 1186/s12885-020-06860-y.

Additional file 1: Figure S1. Forest plot of the comparison of quality of life (QOL).

Additional file 2: Figure S2. Forest plot of the comparison of adverse events (AEs)

\section{Abbreviation}

CIK: Cytokine-induced killer; DC-CIK: Dendritic cell combined with CIK; GIC: Cell therapy in advanced gastrointestinal cancer; WMD: Weighted mean difference; RRs: Risk ratios; Cls: Confidence intervals; OS: Overall survival; TNM: Tumor Node Metastasis; PFS: Progression-free survival; CR: Complete response; PR: Partial response; ORR: Overall response rate; QOL: Quality of life

\section{Acknowledgements}

None.

\section{Authors' contributions}

HS D and J Y carried out the studies, participated in collecting data, and drafted the manuscript. HS D and $Y Z$ performed the statistical analysis and participated in its design. HS D participated in acquisition, analysis, or interpretation of data and draft the manuscript. All authors read and approved the final manuscript.

\section{Funding}

None.

\section{Availability of data and materials}

The datasets used and/or analyzed during the current study are available from the corresponding author on reasonable request.

\section{Ethics approval and consent to participate}

This article is a meta-analysis. The data in this article is from published articles and does not require ethical approval.

\section{Consent for publication}

Not applicable.

\section{Competing interests}

All authors declare that they have no any conflict of interests.

\section{Author details}

'Department of Gastrointestinal Surgery, The Central Hospital of Wuhan, Tongji Medical College, Huazhong University of Science and Technology, Wuhan, China. ${ }^{2}$ Department of Biochemistry \& Molecular Biology, School of Basic Medicine, Tongji Medical College, Huazhong University of Science and Technology, Wuhan, China.

Received: 24 October 2019 Accepted: 13 April 2020 Published online: 28 April 2020

\section{References}

1. Jemal A, Bray F, Center MM, Ferlay J, Ward E, Forman D. Global cancer statistics. CA Cancer J Clin. 2011;61(2):69-90.

2. Japanese Gastric Cancer Association. Japanese gastric cancer treatment guidelines 2014 (ver. 4). Gastric Cancer. 2017;20(1):1-19. PMID: PMC5215069.

3. Suzuki H, Gotoda T, Sasako M, Saito D. Detection of early gastric cancer: misunderstanding the role of mass screening. Gastric Cancer. 2006:9(4):315-9

4. McFarland EG, Levin B, Lieberman DA, Pickhardt PJ, Johnson CD, Glick SN et al. Revised colorectal screening guidelines: joint effort of the American Cancer Society, U.S. multisociety task force on colorectal Cancer, and American College of Radiology. Radiology. 2008;248(3):717-20.

5. Dehghanzadeh R, Jadidi-Niaragh F, Gharibi T, Yousefi M. MicroRNA-induced drug resistance in gastric cancer. Biomed Pharmacother. 2015;74:191-9.

6. Zugazagoitia J, Guedes C, Ponce S, Ferrer I, Molina-Pinelo S, Paz-Ares L. Current challenges in Cancer treatment. Clin Ther. 2016;38(7):1551-66.
7. Lee JH, Lee JH, Lim YS, Yeon JE, Song TJ, Yu SJ, et al. Adjuvant immunotherapy with autologous cytokine-induced killer cells for hepatocellular carcinoma. Gastroenterology. 2015;148(7):1383-91 e1386.

8. Nakagawa S, Matsuoka Y, Ichihara H, Yoshida H, Yoshida K, Ueoka R. New cancer immunotherapy using autologous lymphocytes activated with trastuzumab. Biol Pharm Bull. 2012;35(8):1213-5.

9. Palucka K, Banchereau J. Cancer immunotherapy via dendritic cells. Nat Rev Cancer. 2012;12(4):265-77.

10. Jiang J, Wu C, Lu B. Cytokine-induced killer cells promote antitumor immunity. J Transl Med. 2013;11:83.

11. Yang $T$, Zhang W, Wang L, Xiao C, Wang L, Gong Y, et al. Co-culture of dendritic cells and cytokine-induced killer cells effectively suppresses liver cancer stem cell growth by inhibiting pathways in the immune system. BMC Cancer. 2018;18(1):984.

12. Jiang J, Xu N, Wu C, Deng H, Lu M, Li M, et al. Treatment of advanced gastric cancer by chemotherapy combined with autologous cytokineinduced killer cells. Anticancer Res. 2006:26(3b):2237-42.

13. Shi L, Zhou Q, Wu J, Ji M, Li G, Jiang J, et al. Efficacy of adjuvant immunotherapy with cytokine-induced killer cells in patients with locally advanced gastric cancer. Cancer Immunol Immunother. 2012;61(12):2251-9.

14. Zhao H, Fan Y, Li H, Yu J, Liu L, Cao S, et al. Immunotherapy with cytokineinduced killer cells as an adjuvant treatment for advanced gastric carcinoma: a retrospective study of 165 patients. Cancer Biother Radiopharm. 2013;28(4):303-9.

15. Lin T, Song C, Chuo DY, Zhang H, Zhao J. Clinical effects of autologous dendritic cells combined with cytokine-induced killer cells followed by chemotherapy in treating patients with advanced colorectal cancer: a prospective study. Tumour Biol. 2016;37(4):4367-72.

16. Mu Y, Wang WH, Xie JP, Zhang YX, Yang YP, Zhou CH. Efficacy and safety of cord blood-derived dendritic cells plus cytokine-induced killer cells combined with chemotherapy in the treatment of patients with advanced gastric cancer: a randomized phase II study. Onco Targets Ther. 2016;9: 4617-27.

17. Zhao H, Wang Y, Yu J, Wei F, Cao S, Zhang X, et al. Autologous cytokineinduced killer cells improves overall survival of metastatic colorectal Cancer patients: results from a phase II clinical trial. Clin Colorectal Cancer. 2016; 15(3):228-35.

18. Peng $H$, Yao M, Fan $H$, Song L, Sun J, Zhou Z, et al. Effects of autologous cytokine-induced killer cells infusion in colorectal Cancer patients: a prospective study. Cancer Biother Radiopharm. 2017:32(6):221-6.

19. Wang $Y$, Wang C, Xiao H, Niu C, Wu H, Jin H, et al. Adjuvant treatment combining cellular immunotherapy with chemotherapy improves the clinical outcome of patients with stage II/II gastric cancer. Cancer Med. 2017:6(1):45-53.

20. Xie Y, Huang L, Chen L, Lin X, Chen L, Zheng Q. Effect of dendritic cellcytokine-induced killer cells in patients with advanced colorectal cancer combined with first-line treatment. World J Surg Oncol. 2017;15(1):209.

21. Duval S, Tweedie R. Trim and fill: a simple funnel-plot-based method of testing and adjusting for publication bias in meta-analysis. Biometrics. 2000; 56(2):455-63.

22. Yan Z, Xiong Y, Xu W, Gao J, Cheng Y, Wang Z, et al. Identification of hsamiR-335 as a prognostic signature in gastric cancer. PLoS One. 2012;7(7): e40037.

23. Schmidt-Wolf IG, Negrin RS, Kiem HP, Blume KG, Weissman IL. Use of a SCID mouse/human lymphoma model to evaluate cytokine-induced killer cells with potent antitumor cell activity. J Exp Med. 1991;174(1):139-49.

24. Scheffold $C$, Brandt $K$, Johnston $V$, Lefterova $P$, Degen $B$, Schontube $M$, et al. Potential of autologous immunologic effector cells for bone marrow purging in patients with chronic myeloid leukemia. Bone Marrow Transplant. 1995;15(1):33-9.

25. Schmidt-Wolf IG, Lefterova P, Johnston V, Scheffold C, Csipai M, Mehta BA et al. Sensitivity of multidrug-resistant tumor cell lines to immunologic effector cells. Cell Immunol. 1996;169(1):85-90.

26. Ren $X, Y u$ J, Liu H, Zhang $P, A n X$, Zhang $N$, et al. Th1 bias in PBMC induced by multicycles of auto-CIKs infusion in malignant solid tumor patients. Cancer Biother Radiopharm. 2006:21(1):22-33.

27. Lu PH, Negrin RS. A novel population of expanded human CD3+CD56+ cells derived from T cells with potent in vivo antitumor activity in mice with severe combined immunodeficiency. J Immunol. 1994;153(4):1687-96. 
28. Ishigami S, Natsugoe S, Tokuda K, Nakajo A, Che X, Iwashige H, et al. Prognostic value of intratumoral natural killer cells in gastric carcinoma. Cancer. 2000;88(3):577-83.

29. Wang FS, Liu MX, Zhang B, Shi M, Lei ZY, Sun WB, et al. Antitumor activities of human autologous cytokine-induced killer (CIK) cells against hepatocellular carcinoma cells in vitro and in vivo. World J Gastroenterol. 2002;8(3):464-8.

30. Kim HM, Lim J, Park SK, Kang JS, Lee K, Lee CW, et al. Antitumor activity of cytokine-induced killer cells against human lung cancer. Int Immunopharmacol. 2007;7(13):1802-7.

31. Wang P, Yu JP, Gao SY, An XM, Ren XB, Wang XG, et al. Experimental study on the treatment of intracerebral glioma xenograft with human cytokineinduced killer cells. Cell Immunol. 2008;253(1-2):59-65.

32. Sun $S$, Li XM, Li XD, Yang WS. Studies on inducing apoptosis effects and mechanism of CIK cells for MGC-803 gastric cancer cell lines. Cancer Biother Radiopharm. 2005;20(2):173-80.

33. Wang X, Tang S, Cui X, Yang J, Geng C, Chen C, et al. Cytokine-induced killer cell/dendritic cell-cytokine-induced killer cell immunotherapy for the postoperative treatment of gastric cancer: a systematic review and metaanalysis. Medicine (Baltimore). 2018;97(36):e12230.

34. Zhao M, Li H, Li L, Zhang Y. Effects of a gemcitabine plus platinum regimen combined with a dendritic cell-cytokine induced killer immunotherapy on recurrence and survival rate of non-small cell lung cancer patients. Exp Ther Med. 2014;7(5):1403-7.

35. Ma Y, Xu YC, Tang L, Zhang Z, Wang J, Wang HX. Cytokine-induced killer (CIK) cell therapy for patients with hepatocellular carcinoma: efficacy and safety. Exp Hematol Oncol. 2012;1(1):11.

36. Wang D, Zhang B, Gao H, Ding G, Wu Q, Zhang J, et al. Clinical research of genetically modified dendritic cells in combination with cytokine-induced killer cell treatment in advanced renal cancer. BMC Cancer. 2014;14:251.

37. Li JJ, Gu MF, Pan K, Liu LZ, Zhang H, Shen WX, et al. Autologous cytokineinduced killer cell transfusion in combination with gemcitabine plus cisplatin regimen chemotherapy for metastatic nasopharyngeal carcinoma. $J$ Immunother. 2012;35(2):189-95

38. Schmeel LC, Schmeel FC, Coch C, Schmidt-Wolf IG. Cytokine-induced killer (CIK) cells in cancer immunotherapy: report of the international registry on CIK cells (IRCC). J Cancer Res Clin Oncol. 2015;141(5):839-49.

\section{Publisher's Note}

Springer Nature remains neutral with regard to jurisdictional claims in published maps and institutional affiliations.

Ready to submit your research? Choose BMC and benefit from:

- fast, convenient online submission

- thorough peer review by experienced researchers in your field

- rapid publication on acceptance

- support for research data, including large and complex data types

- gold Open Access which fosters wider collaboration and increased citations

- maximum visibility for your research: over $100 \mathrm{M}$ website views per year

At $\mathrm{BMC}$, research is always in progress.

Learn more biomedcentral.com/submissions 